\title{
Boletus gabretae in Finland
}

\author{
PAAVO KALLIO
}

\begin{abstract}
KALLIO, P. 1984: Boletus gabretae in Finland. - Karstenia 24: 77-78.
Boletus gabretae Pil. was described by Pilát in 1968 from Czechoslovakia. It is close to $B$. junquilleus (Quél.) Boudier, but differs in the reticulated upper part of the stipe. Their affinities with other boletes are discussed. The Finnish locality, at Avensor, Korppoo, is near a limestone quarry.
\end{abstract}

Paavo Kallio, Kevo Subarctic Research Institute, University of Turku, SF-20500 Turku, Finland

\section{Introduction}

In Finland the genus Boletus s.str. has only a few species (Kallio \& Heikkilä 1978), but in Central Europe their number is much higher. Due to its favourable climate and the presence of limestone, the southwestern corner of Finland (Eklund 1931, Hinneri 1972) might be expected to yield new finds of Central European boletes (Kallio 1963, Bresinsky 1969). On August 3, 1974, when visiting Korppoo, Avensor (SW archipelago between Åland and mainland Finland), the author found numerous fruit bodies of Boletus luridus Fries growing around an old limestone quarry. One fruit body of $B$. gabretae Pilát was found near by.

\section{Description of the species}

The asymmetrical cap of the only specimen had a maximum diameter of $8 \mathrm{~cm}$. The surface was velvety and the free margin of the cuticle was clearly observed when fresh, being about $1 \mathrm{~mm}$ wide. The stipe was fasciated, $4.5 \times 2.5 \mathrm{~cm}$ in cross-section, clearly velvety at least in the lower parts, having on overall yellow colour, with grey and brown-yellow tints; the reddish brown colour of the base extended ca. $2 \mathrm{~cm}$ upwards. The upper part (a quarter to a third) of the stipe was covered by a net. When touched, all parts of the stipe turned bluish and then rapidly became very dark blue. The flesh was yellow or yellowish, but changed in a few seconds to blue and darkened rapidly. In this colour the specimen resembled $B$. junquilleus (Quél.) Boudier, described by Watling (1970) as 'brilliant lemon-yellow or lemon chrome with or without flush of luteous ... and tubes lemon chrome, to red ...' That species, however, does not have a reticulated stipe. A yellow bolete with apically reticulated stipe has been described by Pilát (1968) as Boletus gabretae. The specimen from Âvensor, Finland, is almost identical with the species of Pilát, resembling, when touched, Fig. 58a of Pilát and Dermek (1974). That Figure, however, lacks the dark reddish colour at the base of the stipe typical of the Finnish specimen. In this feature our specimen resembles B. jun- quilleus in Fig. 57 of Pilát and Dermek (1974), thought there the red extends up to the cap. The microscopic characters hardly serve to differentiate $B$. junquilleus from B. gabretae (Pilát 1968). The spores of the Finnish material measure $10.4 \times 4.9 \mu \mathrm{m}$, while Pilát gives $12-15 \times 5.5-6 \mu \mathrm{m}$.

Pilát (1968) also discussed the relationships between B. gabretae and B. luridus. He showed that the colour difference is not the only distinguishing character, since these species also differ in their iodine reactions, $B$. luridus having amyloid hyphae. $B$. luri$d u s$ often has a basally reticulated stipe, while in $B$. gabretae the network covers its upper third. The reticulation itself is also different. In B. luridus the mesh is extended lengthwise, while in B. gabretae the mesh is wider (Figs. 1-2).

The specimen found in the same locality in 1979 was identical with that described.

\section{Ecology}

The specimen was growing on a rather open meadow, close to an old limestone quarry. The scattered trees were Betula species, Juniperus communis, Pinus sylvestris seedlings and Sorbus aucuparia. The area has been grazed by cattle. The year 1974 was a good one for fungi. In the locus classicus, Pilát (1968) described the habitat as montane spruce forest, and considered the site too high for $B$. luridus.

Five years after the first find (in 1979), Mr Mauri Karunen, Ph.M., brought me B. luridus and B. gabretae from the same place.

\section{Specimens examined}

Finland. Varsinais-Suomi. Korppoo, Åvensor, close to limestone quarry, 3.VIII. 1974 Kallio (TUR 068151); the same site, 21.VII.1979 Karunen (TUR 063609).

\section{References}

Bresinsky, A. 1969: Zur Erforsschung der europäischen Grosspilzflora. Probleme, Möglichkeiten, Beiträge. $-Z$. Pilzkunde 35: 179-212. 


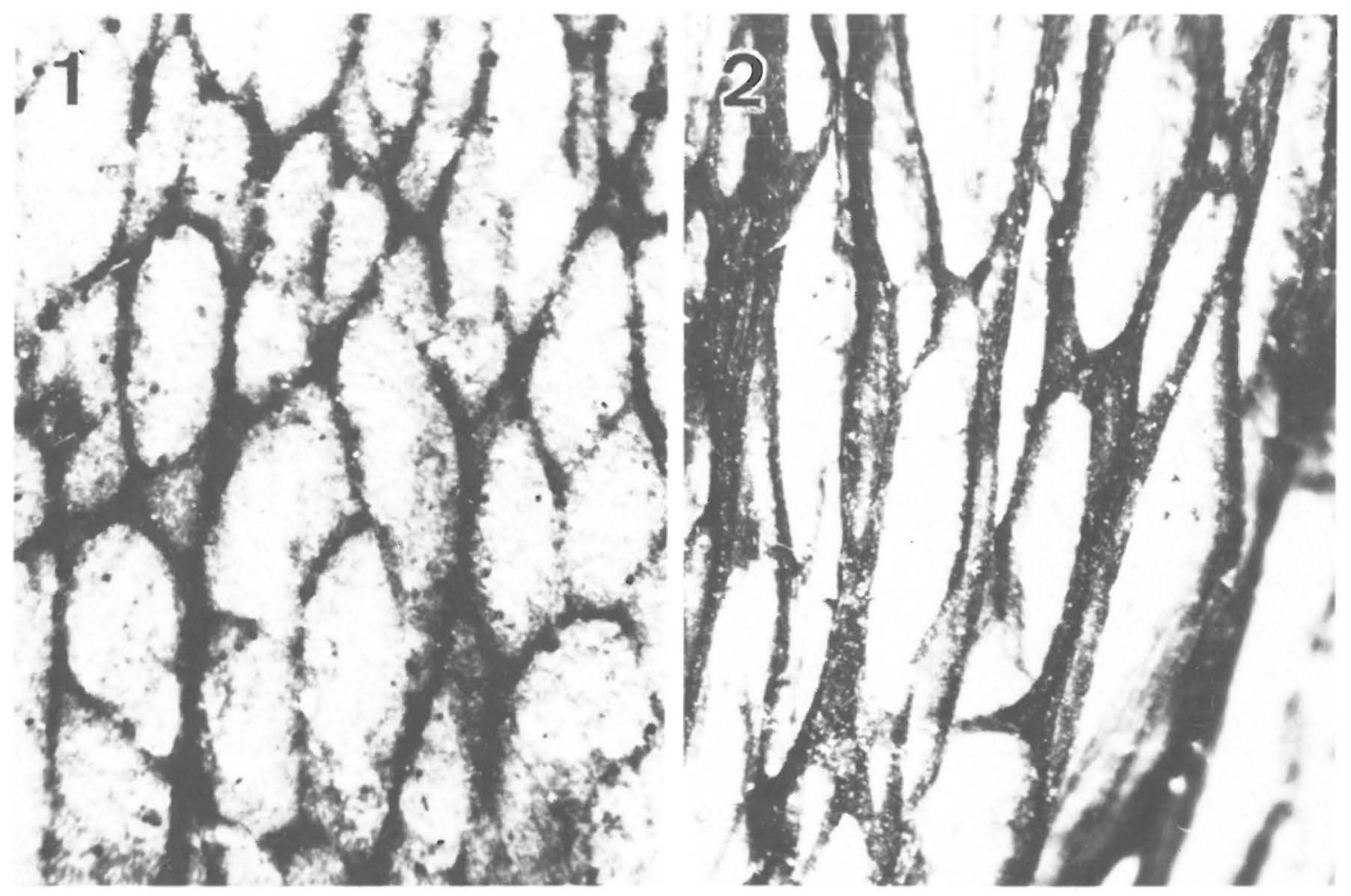

Figs. $1-2$. Reticulum on stipe of two species of Boletus, $\times 10 .-1$ : B. gabretae. -2 : B. luridus.

Eklund, O. 1931: Über die Ursachen der regionalen Verteilung der Schärenflora Südwest-Finnlands. - Acta Bot. Fennica 8: 1-133.

Hinneri, S. 1972: An ecological monograph on eutrophic deciduous woods in the SW archipelago of Finland. Ann Univ. Turku (A2) 50: 1-131.

Kallio, P. 1963: Zur Verbreitung einiger in Finland südlicher Pilze, besonders in der südwestlichen Eichenzone. Karstenia 6-7: 35-76.

Kallio, P. \& Heikkilä, H. 1978: The boletes in Finland 1.
Genus Boletus. - Karstenia 18: 1-19.

Pilát, A. 1968: Boletus gabretae sp.nov. bohemica ex affinitate Boleti junquillei (Quél.) Boud. - Ceská Mykologie 22: $167-170$.

Pilát, A. \& Dermek, A. 1974: Hribovité huby. - 106 pp., 103 tab. Bratislava.

Watling, R. 1970: Boletaceae, Gomphidiaceae, Paxillaceae. - In: Henderson, D.M., Orton, P.D. and Watling, R. (eds.), British fungus flora 1: 1-112. Edinburgh. 